Ambiguity Tolerance in Career Decision Making 1

Running head: Ambiguity Tolerance in Career Decision Making

The Role of Ambiguity Tolerance in Career Decision Making

Hui Xu

Terence J. G. Tracey

Arizona State University

This project was supported by the Arizona State University Graduate and Professional

Student Association's JumpStart Grant Program. Correspondence should be addressed to Hui Xu, Counseling \& Counseling Psychology, MC-0811, Arizona State University, Tempe, AZ, 85287-0811 (huixu5@asu.edu).

March 25, 2014 


\begin{abstract}
ion
The role of ambiguity tolerance in career decision making was examined in a sample of college students $(n=275)$. Three hypotheses were proposed regarding the direct prediction of ambiguity tolerance on career indecision, the indirect prediction of ambiguity tolerance on career indecision through environmental and self exploration, and the moderation effect of ambiguity tolerance on the link of environmental and self exploration with career indecision. Results supported the significance of ambiguity tolerance with respect to career indecision, finding it directly predicted general indecisiveness, dysfunctional beliefs, lack of information, and inconsistent information, and moderated the prediction of environmental exploration on inconsistent information. The implications of this study are discussed and suggestions for future research are provided.
\end{abstract}

Key words: Ambiguity tolerance, Career exploration, Career indecision, Career Counseling 
The Role of Ambiguity Tolerance in Career Decision Making

Career decision making is a highly ambiguous process as evidenced by the lack of clear criteria for the optimal career choice and the existence of information unavailability and inconsistency in the process. Thus one could argue that individuals who can handle the ambiguity well tend to have better career decision outcomes. While there has been extensive research investigating how people should collect and utilize the information to select a career (Nauta, 2010; Spokane, Meir, \& Catalano, 2000), there has been much less research investigating the effect of information unavailability and inconsistency tolerance on career decision making. The focus of this study was to examine the role of ambiguity tolerance in career decision making.

\section{Ambiguity Tolerance}

Ambiguity tolerance (AT) has been defined as the way individuals perceive and respond to ambiguous situations or stimuli characterized by an array of unfamiliar, complex, or inconsistent clues (Budner, 1962; Furnham \& Ribchester, 1995). According to Furnham and Ribchester (1995), people with low levels of ambiguity tolerance tend to experience stress, react prematurely, and avoid ambiguous stimuli, while those with high ambiguity tolerance perceive ambiguous situations/stimuli as desirable and interesting and do not deny or distort the complexity of incongruity.

Numerous studies in the business and organizational psychology literature have investigated the positive role of ambiguity tolerance in entrepreneur inclination and performance given the fact that entrepreneurs' job is to make decisions under ambiguity. Koh (1996) reported a strong positive relationship between measures of ambiguity tolerance and an individual's entrepreneurial inclination. Begley and Boyd (1988) also reported that 
established entrepreneurs had higher ambiguity tolerance than the small business managers. Wagener, Gorgievski, and Rijsdijk (2010) and Schere (1982) supported ambiguity tolerance being a characteristic distinguishing entrepreneurs from managers as entrepreneurs will face more ambiguous and uncertain situations. Endres, Chowdhury, and Milner (2009) found support for the link of ambiguity tolerance with self-efficacy in a complex decision task, suggesting the positive role of ambiguity tolerance in ambiguous decision making situations. On a whole, ambiguity tolerance was portrayed by the research as an essential competency and characteristic for entrepreneurs (Morris, Webb, Fu, \& Singhal, 2013; Ng, 2013), suggesting that ambiguity tolerance is related to decision making quality in conditions of ambiguity.

In addition, the research is very clear regarding the link of ambiguity intolerance with anxiety disorder symptoms. Dugas, Gagnon, Ladouceur, and Freeston (1998) demonstrated that ambiguity intolerance was pivotal in distinguishing Generalized Anxiety Disorder patients from non-clinical subjects, suggesting that ambiguity intolerance was related to excessive worry about future. In non-clinical samples research has also revealed the association of ambiguity intolerance with worry, obsessions/compulsions, and panic sensations (Buhr \& Dugas, 2006; Dugas, Gosselin, \& Ladouceur, 2001). Excessive worry and anxiety has been found to be the risk factor for impaired decision-making as it results in attention, memory, and interpretation biases, depletion of cognitive resources, and loss of emotional control (De Visser et al., 2010; Miu, Heilman, \& Houser, 2008). Thus, one could expect that ambiguity intolerance would be associated with career decision-making in a negative way.

Given the empirical evidence for the importance of ambiguity tolerance with respect to decision making under ambiguity and the association of ambiguity intolerance with detrimental anxiety, it is plausible to suggest that ambiguity tolerance would be associated 
with career decision making. We proposed that people with lower ambiguity tolerance would have more anxiety in the career decision making process since ambiguity is an inevitable and crucial part of career decision making and consequently they would tend to have more career indecision. Additionally, both environmental and self exploration would be expected to mediate the relation of ambiguity tolerance with career indecision.

Environmental exploration (EE) and self exploration (SE) are emphasized in Parsons' model (1909) that individuals collect information about the self (e.g., interests, values, and personality), about the vocational world (e.g., salaries, requirements, and duties), and then use the information collected in the first two steps to find an area of match. $\mathrm{Xu}, \mathrm{Hou}$, and Tracey (in press) found support for the link of both environmental and self exploration with career indecision, although the magnitude of the link was only moderate. As argued before, individuals with high ambiguity tolerance are likely to feel less anxiety in the ambiguous career exploration process. Thus it is plausible to suggest that those people tend to be more proactive in the career exploration process instead of withdrawing from it. We proposed that ambiguity tolerance indirectly predicted career indecision through both environmental and self exploration, as high ambiguity tolerance would lead to more information gathering (i.e., environmental and self exploration) and then lead to less career indecision. However, there is direct prediction of ambiguity tolerance on career indecision, which is distinct from information gathering.

The unique importance of ambiguity tolerance with respect to decision outcomes has been supported in the economics decision-making studies (e.g., Tversky \& Kahneman, 1981). Kahneman and Tvesky's ground breaking work (1981) has shown that individuals make their decisions not only based on the information available but based on their preference for ambiguity as well. This challenged the rational choice theory, which only emphasizes the information gathering and processing but ignores the inevitable information unavailability 
and inconsistency. The cluster analytic literature has also identified a group of informed indecisive individuals (Larson, 1988). They were well informed but still reported high ambiguity in their decision-making, suggesting that ambiguity cannot be eliminated simply through getting more information but needs another coping process for a better adaptation. Therefore, we hypothesized that there is direct prediction of ambiguity tolerance on career indecision, as individuals with high ambiguity tolerance are more likely to handle the inevitable information unavailability and inconsistency well and thus result in less career indecision.

Additionally ambiguity tolerance was expected to moderate the relation of both environmental and self exploration with career indecision, because individuals with high ambiguity tolerance are more likely to use the information collected in career exploration to make a career decision, while ambiguity intolerant people might feel intimidated by the information limitedness and conflicts encountered in the career exploration process and thus get stuck in the decision process. In other words, ambiguity tolerance could adjust the effectiveness of both environmental and self exploration on career indecision.

\section{Career Indecision}

However, the research has demonstrated that career indecision is not a unidimensional construct (e.g., Brown et al., 2012; Gati, Krausz, \& Osipow, 1996). Gati, Krausz, and Osipow's multidimensional model of career indecision (1996) was developed based on an adaptation of decision making theory to the context of career decisions. It proposed three overarching domains of career indecision, consisting of lack of readiness, lack of information, and inconsistent information. Lack of readiness describes career indecision due to the three indicators of lack of motivation, traits-like indecisiveness, and dysfunctional beliefs. Lack of information describes career indecision due to the four indicators of lack of information about the career decision making process, about self, about occupations, and about ways of 
obtaining additional information. Inconsistent information describes career indecision due to the three indicators of unreliable information, internal conflicts, and external conflicts.

There has been a good deal of data supporting the reliability and validity of this model among college students (e.g., Gati, et al., 1996; Gati \& Saka, 2001; Osipow \& Gati, 1998). However, the previous research has also indicated that the three indicators of the lack of readiness domain diverged from each other as demonstrated in low correlations among the indicators and low alpha coefficients compared to the other two domains (e.g., Gati et al., 1996; Gati \& Saka, 2001; Osipow \& Gati, 1998). This suggested that lack of readiness was not a sound factor. Instead, lack of readiness should be treated more as three distinct indecision types. Based on these previous findings, we specified and adopted a revised model in the current study by breaking down the lack of readiness domain into three indecision types, anticipating that it could achieve a better model-data fit. There would be five domains of career indecision in this revised model, consisting of lack of motivation, general indecisiveness (RI), dysfunctinal beliefs (RD), lack of information (LI), and inconsistent information (II). The revised multi-dimensional model acknowledged the various aspects of career indecision and enabled us to investigate the potentially differential predictions on domains of career indecision. However lack of motivation focused on people's willingness or value for making a career decision, we considered it irrelvant to both explorations and ambiguity tolerance. The other four domains (i.e., general indecisiveness, dysfuntional beliefs, lack of information, and inconsistent information) were expected to relate to ambiguity tolerance as they reflected the dysfunctional reaction to ambiguity and thus would be adopted as the criteria in this study.

Among the four domains of career indecision, dysfunctional beliefs and general indecisiveness are focused on people's dysfunctional cognition and inhibiting indecisiveness in the career decision making process. Ambiguity tolerance was expected to predict these two 
domains directly as high ambiguity tolerant people could handle the anxiety well (Buhr \& Dugas, 2006; Dugas, et al., 1998) and are less likely to have distorted cognition and get stuck in the ambiguous decision making process. However, both environmental and self exploration were seen as irrelevant with these two domains as Xu et al.'s study (in press) showed, because these two domains are more related to how people process the information (e.g., ambiguity tolerance) rather than the amount of exploration.

We hypothesized that ambiguity tolerance directly predicted both lack of information and inconsistent information, because individuals with high ambiguity tolerance could accept the inevitable information unavailability and inconsistency and are capable of making decisions in the condition of inconsistent and complex information (Katsaros \& Nicolaidis, 2012) and thus tend to have less career indecision due to information deficit and inconsistency. Meanwhile, ambiguity tolerance was expected to predict lack of information and information inconsistency indirectly through both environmental and self exploration, since high ambiguity tolerant people are more likely to engage in those ambiguous explorations, which naturally result in greater information amount and higher chance for solving the informational conflicts. We hypothesized ambiguity tolerance moderated the prediction of both environmental and self exploration on lack of information and inconsistent information only, as these two domains are related to the amount of information while the domains of general indecisiveness and dysfunctional beliefs are not related to that.

\section{Research Hypotheses}

To sum up, the model of the hypothesized structural relations was depicted in Figure 1. As noted before, ambiguity tolerance directly predicts all the four career indecision domains (Hypothesis A, see the direct paths of b, c, d, and e). Ambiguity tolerance indirectly predicts lack of information and inconsistent information through both environmental and self exploration (Hypothesis B, see the indirect paths of n, o, p, and q). Ambiguity tolerance 
moderates the relation of environmental and self exploration with lack of information and information inconsistency (Hypothesis $\mathrm{C}$, see the paths of $\mathrm{f}, \mathrm{g}, \mathrm{h}$, and $\mathrm{i}$ from the interaction terms).

\section{Method}

\section{Participants}

The sample consisted of 275 undergraduate students recruited from a southwest state university. They ranged in age from 17 to $29(M=18.43, S D=1.17)$. Of the sample, $40.4 \%$ were male $(n=111)$ and $59.6 \%$ were female $(n=164)$. Of the sample, $4 \%(n=11)$ were at 17 , $67.6 \%(n=186)$ were at $18,20.4 \%(n=56)$ were at $19,5.1 \%(n=14)$ were at 20 , the rest $3 \%$ $(n=8)$ were older than 20. In terms of race/ethnicity, $5.5 \%(n=15)$ were African American/Black, $7.3 \%(n=20)$ were Asian/Asian American, 13.5\% $(n=37)$ were Latino(a)/Hispanic, 64.4\% $(\mathrm{n}=177)$ were Caucasian/White, $1.1 \%(\mathrm{n}=3)$ were Native American, $5.5 \%(n=15)$ were Multiracial, $2.9 \%(n=8)$ were self-identified as others. In terms of major, $93.1 \%(n=256)$ were in an exploratory program and the other $6.9 \%(n=19)$ have declared a major.

\section{Procedure}

College students participating in career development or university orientation classes were invited to participate in this study as an extra credit opportunity. Voluntary participants filled a demographic questionnair and the package of research instruments online. All the individual responses were kept as anonymous and confidential through analysis. According to the setting of the online survey, participants were required to answer all items before they can move to the next part. Thus there were no missing data in the final dataset.

\section{Measurement}

Career Exploration Survey (Stumpf, Colarelli, \& Hartman, 1983). The six-item Environmental Exploration (EE) subscale and the five-item Self-Exploration (SE) subscale of 
CES were designed to assess the degree to which individuals have engaged in environmental-self career exploration activities during the past 3 months. Each subscale was scored on a 5-point Likert scale ranging from 1(very little) to 5 (very much). EE involves exploration regarding occupation, jobs, and organizations (e.g., "Obtained information on specific jobs or companies"), whereas SE includes self-understanding and retrospection (e.g., "Focused my thoughts on me as a person"). Research has revealed internal consistency alpha coefficients ranging from .60 to .88 for the CES subscales (Nauta, 2007; Stumpf, et al., 1983). The validity of the CES was evidenced by its positive association with vocational self-concept crystallization and vocational maturity (Hamer \& Bruch, 1997). The current data revealed an alpha coefficient of .86 for environmental exploration and .83 for self-exploration.

\section{The Multiple Stimulus Types Ambiguity Tolerance Scale-II (MSTAT-II; McLain,} 2009). The MSTAT-II is a 13-item measure designed to measure an individual's tolerance for situations that are unfamiliar, insoluble, or complex (Budner, 1962). The MSTAT-II measures the participants' degree of ambiguity tolerance based on five stimulus types: ambiguous stimuli in general, complex stimuli, uncertain stimuli, new/unfamiliar/novel stimuli, and insoluble/illogical/internally inconsistent stimuli (e.g., "I try to avoid situations that are ambiguous" and "I prefer familiar situations to new ones"). Items would be rated on a 5-point Likert scale ranging from 1 (strongly disagree) to 5 (strongly agree). Higher scores indicate higher ambiguity tolerance. McLain (2009) reported the Cronbach's alpha of .83. Validity evidence of high correlations with other common ambiguity tolerance measures and risk taking propensity and low correlation with social desirability were reported as well (McLain, 2009). The current data revealed an alpha coefficient of .76.

The Career Decision-making Difficulty Questionnaire (CDDQ; Gati et al., 1996). The CDDQ was established based upon Gati and his colleagues' taxonomy of career 
decision-making difficulties (1996). The 3-item General Indecisivenss (RI) scale measures career indecision due to inhibiting indecisiveness (e.g., "It is usually difficult for me to make decisions"). The 4-item Dysfunctional Beliefs (RD) scale measures career indecision due to dysfunctional cognition (e.g., "I believe there is only one career that suits me."). The 12-item Lack of Informtion (LI) scale measures career indecision due to information deficit (e.g., "I find it difficult to make a career decision because I still do not know which occupations interest me"). The 10-item Inconsistent Information (II) scale measure career indecision due to informational conflicts (e.g.. "I find it difficult to make a career decision because I have contradictory data about the existence or the characteristics of a particular occupation or training program"). Participants were asked to rate on a 9-point Likert scale ranging from 1 (does not describe me) to 9 (describes me well). Gati, Ryzhik, and Vertsberger (2013) reported the alpha coefficients of the four scale as $.64, .61, .89$, and .79 for the RI, RD, LI, and II scales respectively. Osipow and Gati (1998) found a strong positive association of the CDDQ with the Career Decision Scale and a strong negative association of the CDDQ with the Career Decision-Making Self-Efficacy Scale, providing evidence for the validity of the CDDQ. The current study found the alpha coefficients of .72, .63, .93, and .89 for the RI, RD, LI, and II scales respectively.

\section{Analysis}

Mplus 7 was employed to conduct the latent variable Structural Equation Modeling (SEM). The manifest items of CES enviromental and self exploration scales were used as the indicators of the latent environmental exploration and self exploration. The mean for the five subscales of MSTAT-II, corresponding to the five theoretical stimulus types, were used as the indicators of the latent ambiguity tolerance. The manefest items of the RI and RD subscales of CDDQ were used as the indicators of the latent RI and RD domains. The subscales under the domains of LI and II were used as the indicators of the latent LI and II domains. The 
latent variable SEM enabled us to examine the structural relations without the the confound of the measurement error and thus result in a more precise examiantion. The fit of the models would be evaluated using the criteria recommended by $\mathrm{Hu}$ and Bentler (1999): robust chi-square, CFI, RMSEA, and SRMR. With the purpose of making the statistical tests robust to non-normality, we adopted the robust maximum likelihood parameter estimation. A nested model comparison approach was used to precisely examine which model represented the data better. Differences between nested models were compared using the Santorra-Bentler scaled chi-square difference test (Muthén \& Muthén, 2012).

The latent variable moderation test was conducted with the unconstrained approach (Marsh, Wen, \& Hau, 2004), in which the latent interaction terms were indicated by the multiplication products of the indicators for the latent interacted variables and the simple slops of the interaction terms were tested to see if there were any moderation effects. Following Marsh et al.'s suggestion (2004) we multiplied the ambiguity tolerance indicators by the environmental or self exploration indicators based on the matching of the factor loading rank order to obtain the indicators for the latent interaction terms (i.e., ATxEE and ATxSE in Figure 1). In order to avoide the dependency between the indictors of the latent predictors (i.e., latent ambiguity tolerance and enviromental-self exploration) and the latent interaction terms, we used the residual centering approach (Little, Bovaird, \& Widaman, 2006) to center the latent interaction items, of which the indicators are the residuals for the regression analysis of the raw multiplication products being regressed on the indicators of the latent predictors (i.e., latent ambiguity tolerance and enviromental-self exploration). The SEM bias-corrected bootstrapping approach $(n=1000)$ of mediation test was used in this study given its superior performance in the simulaiton studies (Cheung \& Lau, 2008). As Chung and Lau (2008) suggested if the 95\% confidence interval does not contain zero, then the mediation effect is significant at the alpha level of .05. 


\section{Results}

Table 1 showed the means, standard deviations, and bivariate correlations of environmental exploration, self-exploration, ambiguity tolerance, and domains of career indecision. Table 2 summarized the fit indices of all the models. We first examined the measurement model of the proposed model (Model 1).

The measurement model was found to fit the data very well with respect to the RMSEA (.045) and SRMR (.063), however the CFI (.88) was below ideal levels. An examination of the modification indices as well as the model residuals did not reveal any major areas of misfit that could be corrected. Given the excellent fit of two of important indicators and lack of information regarding alteration, the model was viewed as an adequate representation of the data. The individual factor loadings for all latent factors were found to be significant and of moderate to large magnitude, further supporting the structure validity of all the latent variables. We then examined the full structural model of the proposed model (Model 2). As can be seen by the values of CFI (.88), RMSEA (.046), and SRMR (.068), this model fit the data adequately. However, the modification indices indicated that one path from environmental exploration to dysfunctional beliefs should be added. Thus, we specify a modified model (Model 3) based on Model 2 but adding the direct prediction of environmental exploration on dysfunctional beliefs (Path m). Model 3 was found to fit the data adequately, as can be seen by the values of CFI (.88), RMSEA (.045), and SRMR (.065). The corrected chi-square test was not significant, scaled $\Delta \chi 2(11, \mathrm{~N}=275)=13.25, p>.05$, indicating that the modified model (Model 3) did not omit important paths and represented the data as well as the saturated measurement model. The examination of the individual regression coefficients revealed 6 non-significant paths.

We then used these results to specify a more parsimonious model (Model 4) by dropping the non-significant relations in Model 3. As can be seen by the values of CFI (.88), RMSEA 
(.044), and SRMR (.066), this model was found to fit the data adequately as well. The scaled chi-square test indicated that this model did not significantly worsen the model-data fit compared to the complete model 3 and the measurement model, scaled $\Delta \chi 2(8, \mathrm{~N}=275)=$ $4.45, p>.05$, and scaled $\Delta \chi 2(19, \mathrm{~N}=275)=17.26, p>.05$. It was noticed that several loadings for the interaction terms were relatively low (.30s .40s). Given the complex nature of the interaction constructs, it is hard to expect that the interaction terms all have high loadings. However, in order to further improve the model-data fit, we specified a simplified model (Model 5) by dropping the interaction term (i.e., ATxSE) which was not found to predict the indecision domains. This model was revealed to fit the data well, as can be seen by the values of CFI (.90), RMSEA (.050), and SRMR (.067). Thus this model was endorsed as the final model (see Figure 2 for all the standardized coefficients).

Regarding the Hypothesis A (i.e., the direct effects), Ambiguity tolerance was found to directly predict all four indecision types (Path $b=-.44$, Path $c=-.24$, Path $d=-.32$, and Path e $=-.23$ ), indicating individuals with high ambiguity tolerance are more likely to have less general indecisiveness, dysfunctional beliefs, lack of information, and inconsistent information. Regarding the Hypothesis C (i.e., the moderation effect), only the interaction term of ambiguity tolerance with environmental exploration was found to predict inconsistent information (Path $g=-.18$ ), indicating that individuals with high ambiguity tolerance are more likely to benefit from environmental exploration, resulting in less career indecision due to informational conflicts. Regarding the Hypothesis B (i.e., the indirect effects), only environmental exploration was found to predict dysfunctional beliefs (Path $\mathrm{m}=.32$ ) and lack of information (Path $\mathrm{n}=-.10$ ). The bias-corrected bootstrap analysis found $95 \%$ confidence intervals of -.01 .16 and -.05 .00 for the environmental mediation of the ambiguity tolerance-dysfunctional beliefs relation and the environmental mediation of the ambiguity tolerance-lack of information relation respectively, indicating that there is no indirect effect. 


\section{Discussion}

Overall ambiguity tolerance was found to play a significant role in career decision making. It directly predicted general indecisiveness, dysfunctional beliefs, lack of information, and inconsistent information. Also it moderated the prediction of environmental exploration on inconsistent information.

The construct of ambiguity tolerance portrays individual differences in terms of preference or tolerance for ambiguity, which results from unfamiliar, complex, or inconsistent clues (Budner, 1962; Furnham \& Ribchester, 1995). Results supported our Hypothesis A well as ambiguity tolerance was found to be predictive of the four domains of general indecisiveness, dysfunctional beliefs, lack of information, and inconsistent information. As previous research showed (Fouad, Cotter, \& Kantamneni, 2009; Gati, et al., 2013), general indecisiveness and dysfunctional beliefs could not be relieved by simply acquiring more information, suggesting that they are more chronic issues and need an adjustment on the characteristic information processing style. The current result is resonant with these arguments that how people handle the ambiguity is closely associated with the issues of general indecisiveness and dysfunctional beliefs. Individuals who are tolerant with the inevitable ambiguity in the career decision making process are less likely to have distorted career beliefs and get stuck in the outcome optimization process. One core characteristic of dysfunctional beliefs and general indecisiveness is the rigid and compulsive pursuit of an optimal choice, which is believed to be somewhere (Schwartz et al., 2002; Turner, Rim, Betz, \& Nygren, 2012). However there are simply no clear criteria for a best choice and there are always risks in people's pursuit of their career aspirations. Thus, a more functional strategy seems to be accepting the inevitable ambiguity in career decision making and engaging in a tentative choice instead of investing excessive time and energy on figuring out the best choice, as the current result suggested. 
The direct association of ambiguity tolerance with lack of information and inconsistent information found in this study is interesting when combined with the studies investigating the link of information gathering with these two domains (e.g., Xu, et al., in press). According to Parsons (1909)'s model, one could expect that information gathering in the domains of the self and the vocational world is heavily predictive of career indecision, especially the information related domains of indecision (i.e., lack of information and inconsistent information). However, Xu et al. (in press) found environmental and self exploration only have at most moderate prediction on lack of information and inconsistent information, suggesting that the amount of information is indeed related to those two information laden indecision issues but the association strength is much smaller than the theory hypothesized. There has been research supporting the proposition that information deficit and conflicts could be the products of another process distinctive from information gathering. Kelly and Shin (2009) revealed the association of neuroticism with information deficit, suggesting that individual difference plays a role in the feeling of information deficit. Brown et al.'s factor analytic work of career indecision (2012) found that information deficit and chronic commitment anxiety were loaded on the same factor. The current study is an extension of these previous studies in the sense of explicitly investigating the unique prediction ambiguity tolerance has on lack of information and inconsistent information in addition to both environmental and self exploration. Results supported the proposition that beyond information collecting people's ambiguity tolerance is additionally beneficial for the relief of information deficit and conflicts and the magnitude of this effect is medium to large as the current data indicated. Based on the current results, in order to help individuals with career indecision due to lack of information and inconsistent information, working with clients on their ambiguity tolerance is suggested as another important and potentially fruitful agenda in career counseling. 
Results only partially supported the Hypothesis $\mathrm{C}$ that the moderation effect of ambiguity tolerance was only found on the link of environmental exploration with inconsistent information. It indicated that individuals with high ambiguity tolerance could better use the information gathered in environmental exploration to solve the informational conflicts, whereas ambiguity intolerant individuals are less likely to integrate the unreliable or conflictual information through gathering more information about the vocational world. As Parsons' model (1909) advocated, amount of information regarding the self and the vocational world is critical. However the current result is suggesting that attuning environmental exploration to client's ambiguity tolerance level is clinically meaningful as heavy environmental exploration without high ambiguity tolerance could be fruitless and even result in more information conflicts. Xu et al. (in press) found from a Chinese sample that both environmental and self exploration predicted lack of information and only self exploration predicted inconsistent information. The present data however presented a different structural pattern, which might indicate a cultural factor playing a role in the link of career exploration with career indecision. More research is thus needed in order to investigate the mechanism in which cultural contexts come into play.

The bootstrap examination did not reveal the mediation effect of either environmental exploration or self exploration on the link of ambiguity tolerance with lack of information and inconsistent information, thus the Hypothesis B was not supported. This finding mainly resulted from the weak or non-significant relation of environmental exploration and self exploration with lack of information and inconsistent information, which resonated again with Xu et al.'s study (in press), suggesting that environmental and self career exploration seem to play a less critical role in career decision making as opposed to the one Parsons proposed (1909).

On a whole, the current results are promising that the significance of ambiguity tolerance 
in career decision making is well supported. An adaptive handling of information unavailability and inconsistency (i.e., tolerance with ambiguity) was found to not only be associated with the relief of the chronic career indecision (i.e., general indecisiveness and dysfunctional beliefs) and the informational career indecision (i.e., lack of information and inconsistent information), but adjust the effectiveness of environmental exploration on information integration as well. Thus this study implied that it is important and necessary to help clients endorse an adaptive coping strategy of information unavailability and inconsistency in career counseling.

This study investigated the structural relations of the variables in a sample of mainly freshman college students. Thus the results might not generalize to other populations. A revised model based on Gati et al.'s taxonomy of career indecision (1996) was adopted in this study. The current data supported its structural validity, but more validity evidence is still needed from future research. Certainly the current data are only cross sectional, so a longitudinal examination of the relations over time is needed to tease out mediation and direct effects. Also, it would be interesting to see future research investigating the interplay of ambiguity tolerance, self-efficacy, and ambiguity perception in career decision making. It is plausible to argue that the interplay of these variables could predict career indecision and career choice as well, since ambiguity aversion affects the financial choice (Tversky \& Kahneman, 1981) and self-efficacy is found to be a central variable in career decision making (Lent, Brown, \& Hackett, 1994). It would be also meaningful to investigate the antecedents of ambiguity tolerance in order to inform the career counseling practice of the feasible intervention strategies. 


\section{References}

Begley, T. M., \& Boyd, D. P. (1988). Psychological characteristics associated with performence in entrepreneurial firms and smaller businesses. Journal of Business venturing, 2, 79-93.

Brown, S. D., Hacker, J., Abrams, M., Carr, A., Rector, C., Lamp, K., . . Siena, A. (2012). Validation of a Four-Factor Model of Career Indecision. Journal of Career Assessment, 20, 3-21. doi: 10.1177/1069072711417154.

Budner, S. (1962). Intolerance of ambiguity as a personality variable. Journal of personality.

Buhr, K., \& Dugas, M. J. (2006). Investigating the construct validity of intolerance of uncertainty and its unique relationship with worry. Journal of Anxiety Disorders, 20, 222-236.

Cheung, G., \& Lau, R. (2008). Testing mediation and suppression effects of latent variables: Bootstrapping with structural equation models. Organizational Research Methods, 11, 296-325.

De Visser, L., Van Der Knaap, L., van de Loo, A., van der Weerd, C., Ohl, F., \& Van Den Bos, R. (2010). Trait anxiety affects decision-making differently in healthy men and women: towards gender-specific endophenotypes of anxiety. Neuropsychologia, 48, 1598-1606.

Dugas, M. J., Gagnon, F., Ladouceur, R., \& Freeston, M. H. (1998). Generalized anxiety disorder: A preliminary test of a conceptual model. Behaviour research and therapy, $36,215-226$.

Dugas, M. J., Gosselin, P., \& Ladouceur, R. (2001). Intolerance of uncertainty and worry: Investigating specificity in a nonclinical sample. Cognitive Therapy and Research, 25, 
$551-558$.

Endres, M. L., Chowdhury, S., \& Milner, M. (2009). Ambiguity tolerance and accurate assessment of self-efficacy in a complex decision task. Journal of Management \& Organization, 15, 31-46.

Fouad, N., Cotter, E., \& Kantamneni, N. (2009). The Effectiveness of a Career Decision-Making Course. Journal of Career Assessment, 17, 338-347. doi: $10.1177 / 1069072708330678$

Furnham, A., \& Ribchester, T. (1995). Tolerance of ambiguity: A review of the concept, its measurement and applications. Current Psychology, 14, 179-199.

Gati, I., Krausz, M., \& Osipow, S. H. (1996). A taxonomy of difficulties in career decision making. Journal of Counseling Psychology, 43, 510-526.

Gati, I., Ryzhik, T., \& Vertsberger, D. (2013). Preparing Young Veterans for Civilian Life: The Effects of a Workshop on Career Decision-Making Difficulties and Self-Efficacy. Journal of Vocational Behavior, 83, 373-385.

Gati, I., \& Saka, N. (2001). Internet-Based Versus Paper-and-Pencil Assessment: Measuring Career Decision-Making Difficulties. Journal of Career Assessment, 9, 397-416.

Hamer, R. J., \& Bruch, M. A. (1997). Personality factors and inhibited career development: Testing the unique contribution of shyness. Journal of Vocational Behavior, 50, $382-400$.

Hu, L., \& Bentler, P. M. (1999). Cutoff criteria for fit indexes in covariance structure analysis: Conventional criteria versus new alternatives. Structural Equation Modeling: A Multidisciplinary Journal, 6, 1-55.

Katsaros, K. K., \& Nicolaidis, C. S. (2012). Personal Traits, Emotions, and Attitudes in the Workplace: Their Effect on Managers' Tolerance of Ambiguity. The Psychologist-Manager Journal, 15, 37-55. 
Kelly, K. R., \& Shin, Y. J. (2009). Relation of Neuroticism and Negative Career Thoughts and Feelings to Lack of Information. Journal of Career Assessment, 17, 201-213.

Koh, H. C. (1996). Testing hypotheses of entrepreneurial characteristics: a study of Hong Kong MBA students. Journal of Managerial Psychology, 11, 12-25.

Larson, L. M., Heppner, P. P., Ham, T., \& Dugan, K. (1988). Investigating multiple subtypes of career indecision through cluster analysis. Journal of Counseling Psychology, 35, 439-446.

Lent, R. W., Brown, S. D., \& Hackett, G. (1994). Toward a unifying social cognitive theory of career and academic interest, choice, and performance. Journal of Vocational Behavior, 45, 79-122.

Little, T. D., Bovaird, J. A., \& Widaman, K. F. (2006). On the merits of orthogonalizing powered and product terms: Implications for modeling interactions among latent variables. Structural Equation Modeling, 13, 497-519.

Marsh, H. W., Wen, Z., \& Hau, K.-T. (2004). Structural equation models of latent interactions: evaluation of alternative estimation strategies and indicator construction. Psychological methods, 9, 275-300.

McLain, D. L. (2009). Evidence Of The Properties Of An Ambiguity Tolerance Measure: The Multiple Stimulus Types Ambiguity Tolerance Scale-II (Mstat-II). Psychological Reports, 105, 975-988.

Miu, A. C., Heilman, R. M., \& Houser, D. (2008). Anxiety impairs decision-making: Psychophysiological evidence from an Iowa Gambling Task. Biological psychology, $77,353-358$.

Morris, M. H., Webb, J. W., Fu, J., \& Singhal, S. (2013). A Competency - Based Perspective on Entrepreneurship Education: Conceptual and Empirical Insights. Journal of Small Business Management, 51, 352-369. 
Muthén, L. K., \& Muthén, B. O. (2012). Chi-Square Difference Testing Using the Satorra-Bentler Scaled Chi-Square, from http://www.statmodel.com/chidiff.shtml

Nauta, M. M. (2007). Career Interests, Self-Efficacy, and Personality as Antecedents of Career Exploration. Journal of Career Assessment, 15, 162-180. doi: $10.1177 / 1069072706298018$.

Nauta, M. M. (2010). The Development, Evolution, and Status of Holland's Theory of Vocational Personalities: Reflections and Future Directions for Counseling Psychology. Journal of Counseling Psychology, 57, 11-22. doi: 10.1037/a0018213

Ng, D. (2013). Seeing through the fog of ambiguity: Entrepreneurial judgments under decision settings of complexity. Human Systems Management, 32, 57-66.

Osipow, S., \& Gati, I. (1998). Construct and concurrent validity of the career decision-making difficulties questionnaire. Journal of Career Assessment, 6, 347-364.

Parsons, F. (1909). Choosing a vocation: Houghton Mifflin Company.

Schere, J. L. (1982). Tolerance of Ambiguity as a Discriminating Variable Between Entrepreneurs and Managers. Paper presented at the Academy of management proceedings.

Schwartz, B., Ward, A., Monterosso, J., Lyubomirsky, S., White, K., \& Lehman, D. R. (2002). Maximizing versus satisficing: happiness is a matter of choice. Journal of Personality and Social Psychology, 83, 1178.

Spokane, A. R., Meir, E. I., \& Catalano, M. (2000). Person-Environment Congruence and Holland's Theory: A Review and Reconsideration. Journal of Vocational Behavior, 57, 137-187. doi: http://dx.doi.org/10.1006/jvbe.2000.1771

Stumpf, S. A., Colarelli, S. M., \& Hartman, K. (1983). Development of the Career Exploration Survey (CES). Journal of Vocational Behavior, 22, 191-226.

Turner, B. M., Rim, H. B., Betz, N. E., \& Nygren, T. E. (2012). The maximization inventory. 
Judgment and Decision Making, 7, 48-60.

Tversky, A., \& Kahneman, D. (1981). The framing of decisions and the psychology of choice. Science, 211, 453-458.

Wagener, S., Gorgievski, M., \& Rijsdijk, S. (2010). Businessman or host? Individual differences between entrepreneurs and small business owners in the hospitality industry. The Service Industries Journal, 30, 1513-1527.

Xu, H., Hou, Z., \& Tracey, T. J. (in press). Relation of Environmental and Self Career Exploration with Career Decision-making Difficulties in Chinese Students. Journal of Career Assessment. 
Table 1. Means, Standard Deviations, and Correlations of Variables

\begin{tabular}{|c|c|c|c|c|c|c|c|c|}
\hline & Mean & $\overline{S D}$ & $\overline{\mathrm{EE}}$ & $\overline{\mathrm{SE}}$ & $\overline{\mathrm{AT}}$ & RI & $\mathrm{RD}$ & $\overline{\mathrm{LI}}$ \\
\hline $\mathrm{EE}$ & 2.55 & 0.86 & - & & & & & \\
\hline SE & 3.32 & 0.88 & $.52^{* *}$ & - & & & & \\
\hline AT & 3.21 & 0.44 & $.14^{*}$ & $.25^{* *}$ & - & & & \\
\hline RI & 5.75 & 1.75 & -.09 & .04 & $-.25^{* *}$ & - & & \\
\hline $\mathrm{RD}$ & 4.76 & 1.51 & $20^{* * *}$ & .10 & -.11 & $.16^{* *}$ & - & \\
\hline LI & 4.51 & 1.71 & $-.22^{* *}$ & $-.15^{*}$ & $-.22^{* *}$ & $.43^{* *}$ & .05 & - \\
\hline II & 3.90 & 1.60 & $-.12^{*}$ & -.10 & -.11 & $.28^{* * *}$ & .02 & $.76^{* *}$ \\
\hline \multicolumn{9}{|c|}{ Note. $N=275 . \mathrm{EE}=\mathrm{CES}-$ Environmental Exploration; SE $=$ CES- Self Exploration; AT = } \\
\hline \multicolumn{9}{|c|}{ MSTAT-II; RI = CDDQ-General Indecisiveness; RD = CDDQ-Dysfunctional Beliefs; LI = } \\
\hline \multicolumn{9}{|c|}{ CDDQ - Lack of Information; II = CDDQ - Inconsistent Information. } \\
\hline \multicolumn{9}{|c|}{$* p<.05$} \\
\hline & & & & & & & & \\
\hline
\end{tabular}


Table 2. Summary of Model Fit Index for Model Comparison.

\begin{tabular}{|c|c|c|c|c|c|c|}
\hline & \multirow{2}{*}{$\chi^{2}$} & \multirow{2}{*}{$d f$} & \multirow{2}{*}{ CFI } & \multicolumn{2}{|c|}{ RMSEA } & \multirow{2}{*}{ SRMR } \\
\hline & & & & Estimate & $90 \%$ C. I. & \\
\hline Model 1 Measurement & 1098.81 & 704 & 0.88 & 0.045 & $.040 \sim .050$ & 0.063 \\
\hline Model 2 Structural & 1124.80 & 716 & 0.88 & 0.046 & $.040 \sim .051$ & 0.068 \\
\hline Model 3 Modified Structural & 1111.71 & 715 & 0.88 & 0.045 & $.040 \sim .050$ & 0.065 \\
\hline Model 4 Parsimonious Structural & 1114.11 & 723 & 0.88 & 0.044 & $.039 \sim .049$ & 0.066 \\
\hline Model 5 Final & 922.35 & 544 & 0.90 & 0.050 & $.045 \sim .056$ & 0.067 \\
\hline
\end{tabular}

Note. $N=275$. 


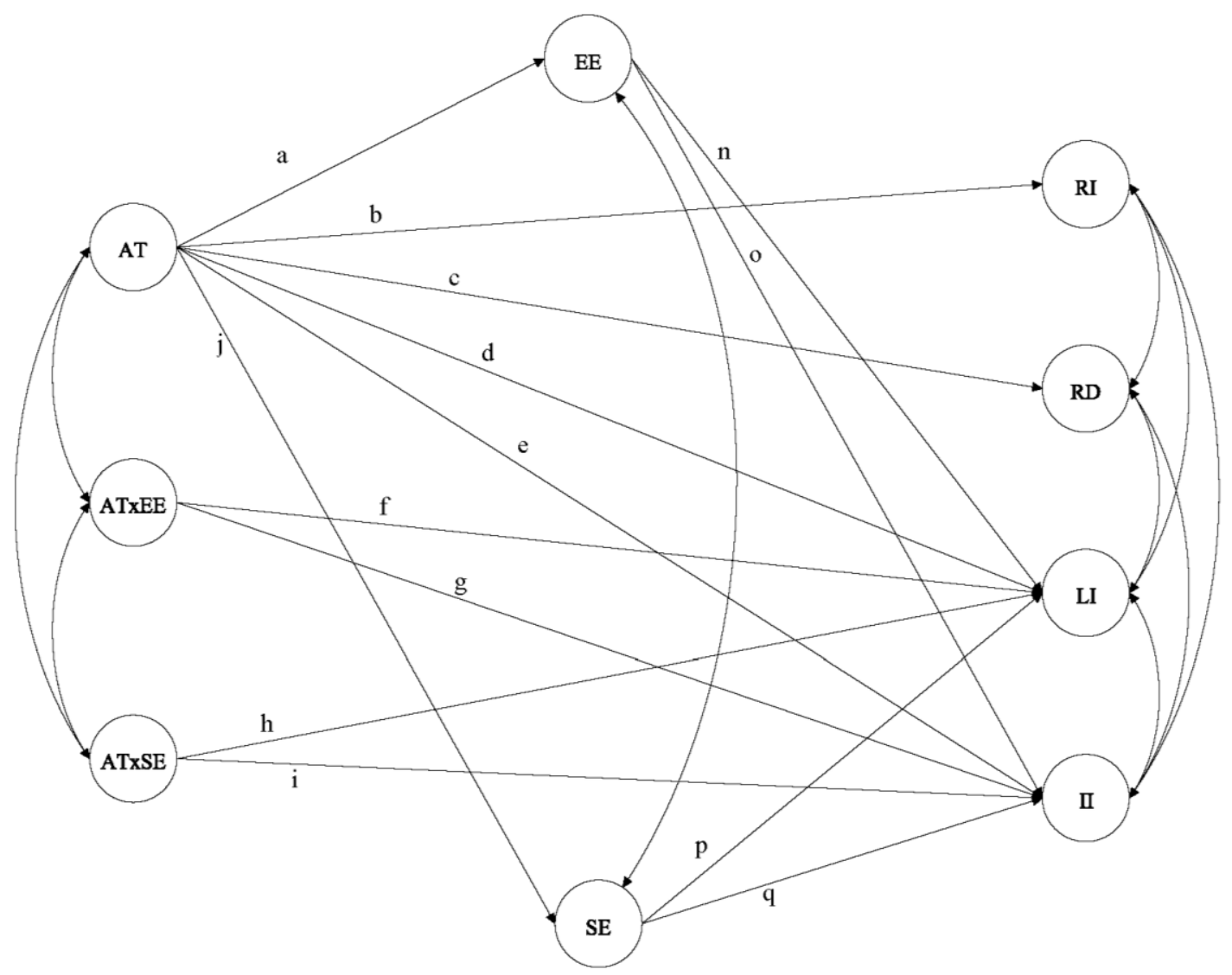

Figure 1. The Hypothesized Model. AT= Anxiety Tolerance; ATxEE= The Interaction Term of Ambiguity Tolerance with Environmental Exploration; ATxSE=The Interaction Term of Ambiguity Tolerance with Self Exploration; EE=Environmental Exploration; SE=Self Exploration; RI=General Indecisiveness; RD=Dysfunctional Beliefs; $\mathrm{LI}=$ Lack of Information; II=Inconsistent Information. 


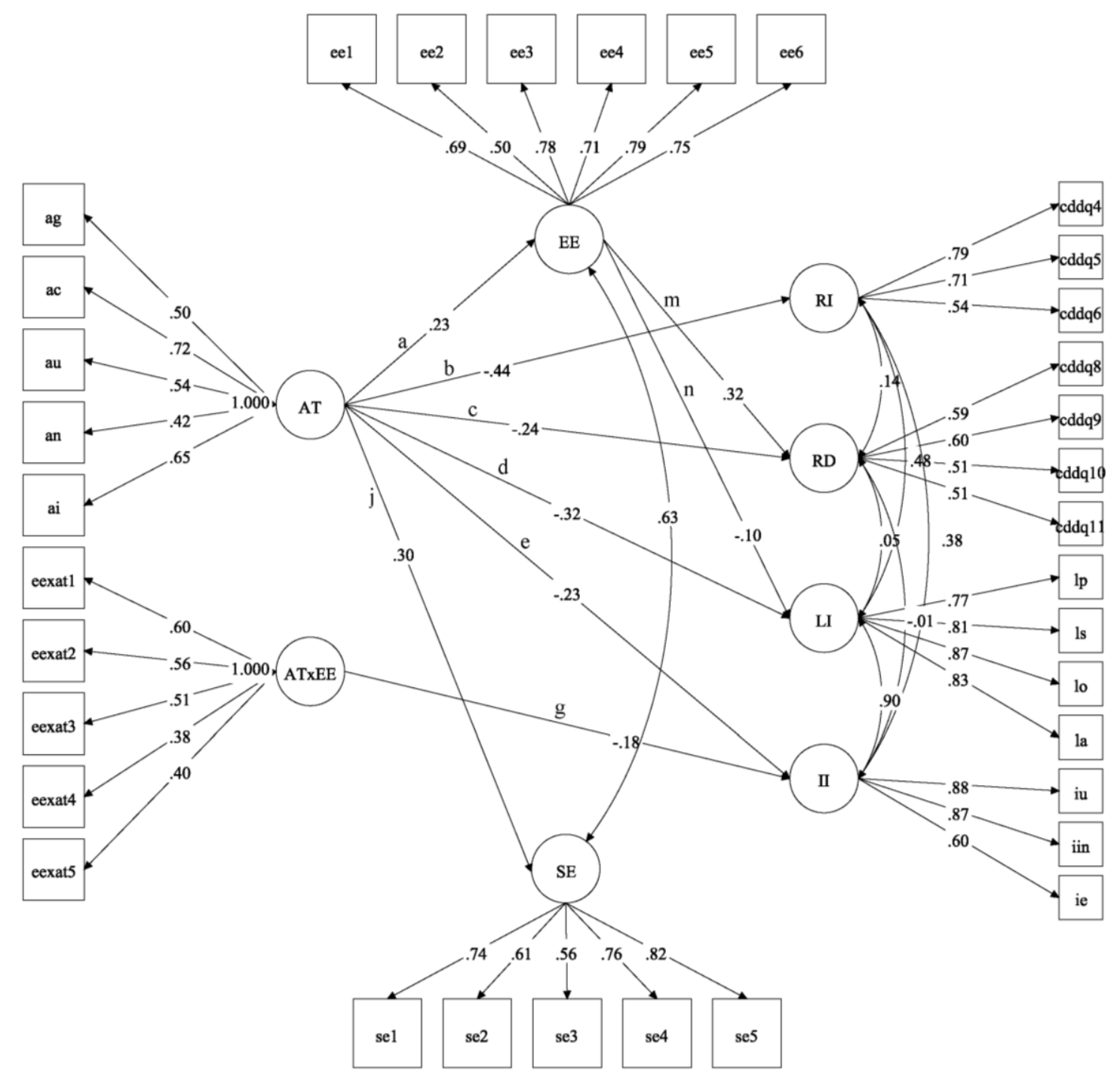

Figure 2. The Final Model. AT= Anxiety Tolerance; ATxEE $=$ The Interaction Term of Ambiguity Tolerance with Environmental Exploration; EE=Environmental Exploration; $\mathrm{SE}=$ Self Exploration; RI=General Indecisiveness; RD=Dysfunctional Beliefs; $\mathrm{LI}=$ Lack of Information; II=Inconsistent Information. 